\title{
Responses of baboon cerebral and extracerebral arteries to prostacyclin and prostaglandin endoperoxide in vitro and in vivo
}

\author{
D. A. J A R M A N, G. H. D U B O U LA Y, B. KE N D A L , \\ A N D D. J. B O U L L I N
}

From the Nuffield Laboratories of Comparative Medicine, Institute of Zoology, London, and MRC Clinical Pharmacology Unit, Radcliffe Infirmary, Oxford

SUMMARY The responses of baboon cerebral and extracerebral arteries to prostaglandin endoperoxide $\left(\mathrm{PGH}_{2}\right)$ and prostacyclin $\left(\mathrm{PGI}_{2}\right)$ were investigated on isolated arteries and in vivo by serial angiography. Both $\mathrm{PGH}_{2}$ and $\mathrm{PGI}_{2}$ could produce dose-dependent contraction or relaxation of isolated arteries. $\mathrm{PGH}_{2}$ induced relaxation was indicative of prostacyclin synthetase activity, the enzyme which converts $\mathrm{PGH}_{2}$ to $\mathrm{PGI}_{2}$. In isolated arteries tested one to four hours post mortem only the vertebral artery showed prostacyclin synthetase activity. Thus $\mathrm{PGH}_{2}$ induced contraction of cerebral arteries may be indicative of a physiological function. Vasomotor tone may in part be the result of a balance between $\mathrm{PGH}_{2}$ constriction and $\mathrm{PGI}_{2}$ dilatation. In vivo $\mathrm{PGI}_{2}$ infusion caused pronounced and prolonged dilatation of cerebral arteries, which lasted longer than the cardiovascular changes. As $\mathrm{PGI}_{2}$ is the most potent cerebral vasodilator drug tested, it may be of clinical use in the treatment of cerebral vasospasm.

Prostacyclin is a recently discovered prostaglandin with potent vasodilator effects on peripheral and central blood vessels. In addition prostacyclin is one of the most potent inhibitors of platelet aggregation known. The potential therapeutic applications of the use of this drug or more stable analogues is currently under study (Moncada and Vane, 1978).

In view of its potent relaxing actions on human and baboon cerebral arteries (Boullin et al., 1979) prostacyclin may be of use in the prevention or reversal of cerebral arterial vasospasm which commonly occurs after the rupture of aneurysms of the major cerebral arteries.

Before any clinical studies it is of course necessary to examine the actions of prostacyclin and precursors (prostaglandin endoperoxides, $\mathrm{PGG}_{2}, \mathrm{PGH}_{2}$ ) upon the cerebral vasculature of animals.

For some years we have been using the baboon as a model for studying the aetiology of human vasospasm (see Boullin et al., 1977, 1978).

Address for reprint requests: Dr D. J. Boullin, MRC Clinical Pharmacology Unit, Radcliffe Infirmary, Oxford OX2 6HE

Accepted 9 January 1979
Accordingly it was relevant to test the effects of prostacyclin and $\mathrm{PGH}_{2}$ on this system.

In this paper we describe their effects on baboon arteries in vitro and in vivo after systemic administration and visualisation by carotid angiography.

In addition to confirming the previous reports of the vasodilator effects of prostacyclin itself, we now find that both $\mathrm{PGH}_{2}$ and prostacyclin can produce constrictor actions in appropriate dosage.

\section{Methods}

\section{ISOLATED ARTERIES}

Male baboons, body weight 6-14 kg, were killed by intravenous injection of pentobarbitone sodium (140 $\mathrm{mg} / \mathrm{kg}$ ). The basilar, vertebral, middle cerebral (MCA), anterior cerebral (Ant CA), abdominal aorta, femoral, and superior mesenteric arteries were removed within one hour of death and placed in Krebs solution (Starling et al., 1975) at $4^{\circ} \mathrm{C}$. Thereafter the tissues were refrigerated for up to four days post mortem. To test the effects of drugs the arteries were dissected spirally and mounted in a $10 \mathrm{ml}$ isolated organ bath. Further 
details are given in previous papers (Starling et al., 1975; Boullin et al., 1976, 1977, 1978). Isotonic contractions of the muscles were amplified by transducer and recorded as previously described.

\section{RESPONSES OF BABOON ARTERIES IN VIVO}

The method for studying drug actions on the calibre of baboon cerebral arteries in vivo is described in detail by Boullin et al. (1978). Animals were anaesthetised with halothane and the major cerebral arteries visualised by sequential carotid angiography using $60 \%$ Urografin 290 (sodium and meglumine diatrizoate). Angiography was performed before and after drug administration. The calibre of the major cerebral arteries was measured before and after drug administration, and the changes expressed as a percentage of the initial values. Drugs were given either intraarterially via a catheter inserted into the common carotid artery or by intravenous injection. Further details are given in Results.

\section{DRUGS}

5-Hydroxytryptamine (5-HT) and noradrenaline (NA) were obtained from Sigma London Chemical Company, Poole, Dorset; dopamine (DM) (as Intropin) from Arnar-Stone Laboratories Ltd, London SW7. These compounds were dissolved in $0.9 \% \mathrm{NaCl}$ solution. Prostaglandin endoperoxide $\left(\mathrm{PGH}_{2}\right)$ and prostacyclin $\left(\mathrm{PGI}_{2}\right)$ are very unstable in aqueous solution (Moncada et al., 1976). $\mathrm{PGH}_{2}$ as the free acid was stored as a stock solution in dry acetone at $-20^{\circ} \mathrm{C}$. Small aliquots were diluted with $50 \mathrm{mM}$ Tris/HC1 buffer $\mathrm{pH} 7.5$ and used immediately. Synthetic $\mathbf{P G I}_{2}$ sodium salt was dissolved in $1 \mathrm{M}$ Tris/HC1 buffer $\mathrm{pH} 8.5$ and further diluted with $50 \mathrm{mM}$ Tris/ $\mathrm{HC1}$ buffer pH 8.5 as required. All drug solutions were kept in ice.

\section{Results}

EFFECTS OF PROSTAGLANDIN ENDOPEROXIDE $\left(\mathrm{PGH}_{2}\right)$ Isolated arteries

Previous workers have found variable effects of $\mathrm{PGH}_{2}$ on arteries from various species. Whereas some vessels are contracted by $\mathbf{P G H}_{2}$, others including coronary and abdominal arteries relax (Moncada et al., 1976; Needleman et al., 1977). We have also observed variable effects on baboon cerebral arteries here. Because $\mathrm{PGH}_{2}$ relaxations are believed to be due to conversion of $\mathrm{PGH}_{2}$ to $\mathrm{PGI}_{2}$ by the enzyme prostacyclin synthetase, we studied the actions of $\mathrm{PGH}_{2}$ at varying times post mortem; we expected $\mathrm{PGH}_{2}$ relaxations to be seen only shortly after death. In fact relaxations were only seen with the verebral artery. All other cerebral arteries produced contractions to $\mathrm{PGH}_{2}$ even when tested one to four hours post mortem as described below.

With regard to $\mathrm{PGH}_{2}$ induced relaxations on the vertebral artery, we made five tests within 48 hours of death and $\mathrm{PGH}_{2}$ caused relaxation each time. Tests made on day 3 produced contraction.

On successive days post mortem typical results are shown in Fig. 1. On day 1, 14-16 hours post mortem the responses to two doses of $\mathrm{PGH}_{2}$ were triphasic: an initial very rapid contraction, then relaxation which gradually was reversed and followed by sustained contraction (Fig. 1, day 1, left record).

At this time cumulative doses of $\mathrm{PGI}_{2}$ produced the typical responses of relaxation with low doses. As will be described below, high concentrations of $\mathrm{PGI}_{2}$ caused contraction (Fig. 1, day 1, right record). On day 2 when the protocols with $\mathrm{PGH}_{2}$ and $\mathrm{PGI}_{2}$ were repeated early in the day $(38-40$ hours post mortem, Fig. 3, record A) the responses to both $\mathrm{PGH}_{2}$ and $\mathrm{PGI}_{2}$ were qualitatively similar to those on day 1 but quantitativelyo greater. Our experience with both human and baboon cerebral arteries is that their responses to drugs are maximal on the second day.

One hour later on day 2 (Fig. 1, record B) however, $\mathrm{PGH}_{2}$ no longer caused relaxation but merely a two phase contraction. At this time PGI responses on the other hand were not altered (records not shown). The pattern of responses of day 2 was repeated on day 3; again $\mathrm{PGH}_{2}$ produced only contraction. Of the peripheral arteries only the femoral artery produced a triphasic response to $\mathrm{PGH}_{2}$ similar to that shown in Fig. 1.

We conclude from the data shown in Fig. 1 that the contractile effects of $\mathrm{PGH}_{2}$ are a direct action on the arterial muscle, while secondary relaxation is mediated by conversion of $\mathrm{PGH}_{2}$ to $\mathrm{PGI}_{2}$ by prostacyclin synthetase present in the walls of the arterial vessels (See Discussion). Therefore it was surprising to find that all other arteries only contracted to $\mathbf{P G H}_{2}$ even when tested within four hours of death. $\mathrm{PGH}_{2}$ caused dose-dependent contractions of all cerebral arteries in concentrations from 0.3 to $100 \mathrm{nmol} / 1$ with no evidence of responses reaching a maximum (Fig. 2). Higher concentrations could not be tested because of shortage of material. Figure 2 shows cumulative dose/response curves for $\mathrm{PGH}_{2}$ on the basilar, vertebral, MCA, and Ant. CA, abdominal aorta, femoral, and superior mesenteric arteries. 


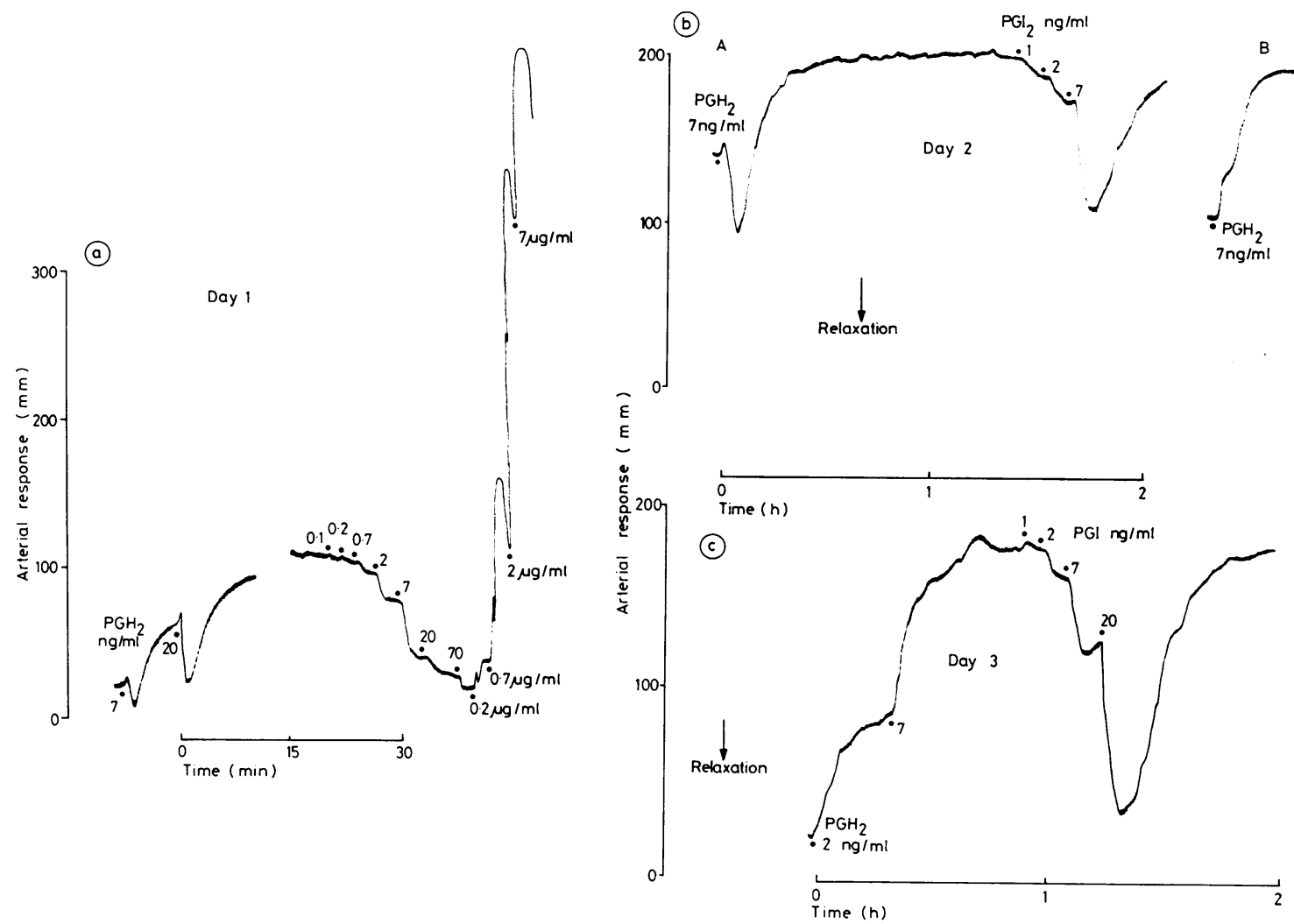

Fig. 1 Prostacyclin synthetase activity of baboon isolated vertebral arteries removed one hour post mortem and tested for activity to $\mathrm{PGH}_{2}$ and $\mathrm{PGI}_{2}$ at the following times post mortem: day 1 (14-16 hours); day 2 (38 hours, $A ; 40$ hours, $B)$; day 3 (64 hours). Transducer amplified contractions or relaxations of arterial muscle where $10 \mathrm{~mm}$ contraction is equivalent to $50 \mathrm{mV}$ recorder response (arterial response, $\mathrm{mm}$, ordinate) are plotted against duration of experimental recording (time, $\mathrm{min}$, abscissa). The results were obtained from one artery tested on successive days. PGH ${ }_{2}$ and $P G I_{2}$ were added to the isolated arteries in the following doses as indicated by the dots. Doses were cumulative for both drugs. (a) Day 1: $\mathrm{PGH}_{2}(\mathrm{ng} / \mathrm{ml}), 7$ and 20. $\mathrm{PGI}_{2}$ doses producing relaxation $(\mathrm{ng} / \mathrm{ml}): 0.1,0.2,0.7,2,7,20$, and 70 , followed by doses causing contraction $(\mu \mathrm{g} / \mathrm{ml}) 0.20 .7,2$, and 7. (b) Day $2 \mathrm{~A}: \mathrm{PGH}_{2} 7 \mathrm{ng} / \mathrm{ml} ; \mathrm{PGI}_{2} \mathrm{I}, 2$, and $7 \mathrm{ng} / \mathrm{ml}$;

B: $\mathrm{PGH}_{2} 7 \mathrm{ng} / \mathrm{ml}$.(c) Day 3: $\mathrm{PGH}_{2} 2$ and $7 \mathrm{ng} / \mathrm{ml} ; \mathrm{PGI}_{2} \mathrm{l}, 2,7$, and $20 \mathrm{ng} / \mathrm{ml}$.

It must be emphasised that on vertebral arteries also, $\mathrm{PGH}_{2}$ produced dose-dependent contractions and that threshold doses caused contraction and not relaxation (Fig. 3); it was not the other way round. Concentrations of $\mathrm{PGH}_{2}$ above $10 \mathrm{nmol} / 1$ produced triphasic responses: an initial transient contraction which was rapidly followed by a relaxation. The last phase of response was a contraction; the second and third phases were dose-dependent.

Arterial calibre in situ

$\mathrm{PGH}_{2}$ was tested in only one experiment because of shortage of material. Doses of 4 and $10 \mu \mathrm{g}$ were injected intra-arterially and angiograms per- formed 4-5 min thereafter. There was no significant change in the calibre of the cerebral vessels examined.

EFFECTS OF PROSTACYCLIN (PGI.)

Isolated arteries

Isolated arteries responded to $\mathrm{PGI}_{2}$ in two ways: low concentrations between 0.3 to $800 \mathrm{nmol} / 1$ caused dose-dependent relaxations; very high concentrations (over $0.8 \mu \mathrm{mol} / \mathrm{l}$ ), probably outside the physiological range (see Discussion), produced dose-dependent contractions. Both types of response are shown in Fig. 1; dose-response curves for $\mathrm{PGI}_{2}$ on various cerebral and extracerebral arteries are shown in Fig. 4a and b. 


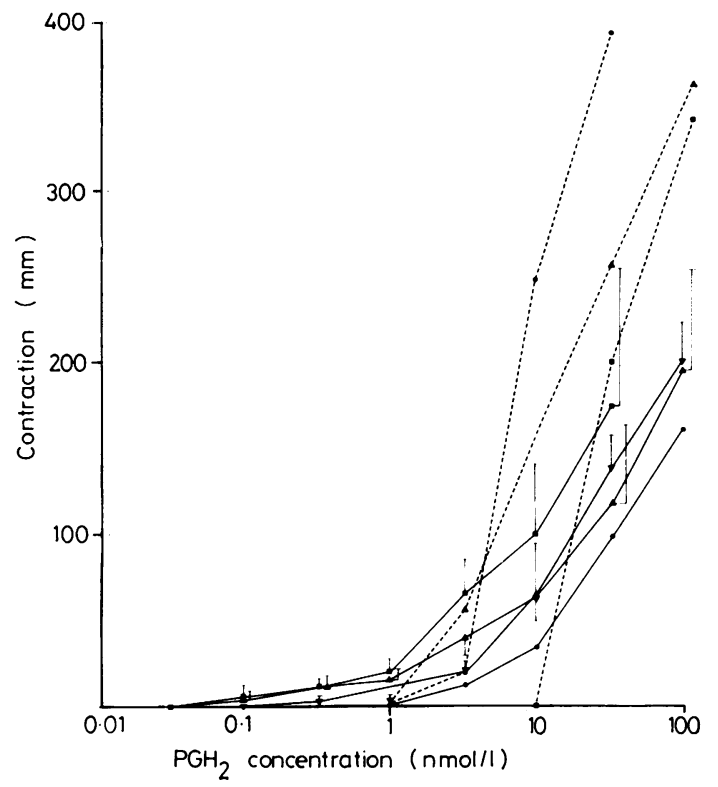

Fig. 2 Dose-response relationships for $\mathrm{PGH}_{2}$ contractions of baboon arteries. Values are mean $\pm S E M$ of three to five experiments with cerebral arteries (solid lines) and single experiments with peripheral vessels (interrupted lines). Contractile responses (ordinate) are plotted against log $\mathrm{PGH}_{2}$ concentration (nmol/1, abscissa). - Basilar artery, $\square$ vertebral artery, $\Delta-\Delta$ anterior cerebral artery, $\boldsymbol{\nabla} \longrightarrow \boldsymbol{\nabla}$ middle cerebral artery, $---\bullet$ femoral artery, - - - abdominal artery, $\mathbf{\Delta - - - \Delta}$ superior mesenteric artery.

\section{Prostacyclin $\left(\mathrm{PGI}_{2}\right)$ in vivo}

The actions of $\mathrm{PGI}_{2}$ on the blood pressure, heart rate, and calibre of cerebral blood vessels were studied in four baboons by sequential angiography $10 \mathrm{~min}$ to three hours after administration.

Five experiments were made as one animal was used twice with an interval of two months between experiments. In four experiments $\mathrm{PGI}_{2}$ was administered systematically and once intracranially into the subarachnoid space using the procedure described by Boullin et al. (1978).

$\mathrm{PGI}_{2}$ was given by intra-arterial infusion in two experiments over $2-10 \mathrm{~min}$ in doses of $68 \mathrm{ng} / \mathrm{kg}$ and $29 \mu \mathrm{g} / \mathrm{kg}(180 \mathrm{pmol} / \mathrm{kg}$ and $77 \mathrm{nmol} / \mathrm{kg})$. These doses produced profound changes in the cardiovascular system (severe hypotension and bradycardia) lasting 20-40 min but there was no change in the calibre of the major cerebral arteries.

We also gave $\mathrm{PGI}_{2}$ by intravenous infusion (femoral vein) in another two experiments. The doses were 4.5 and $13 \mu \mathrm{g} / \mathrm{kg}$ in one experiment and $83 \mu \mathrm{g} / \mathrm{kg}$ in another $(12,35$, and $221 \mathrm{nmol} / \mathrm{kg})$.
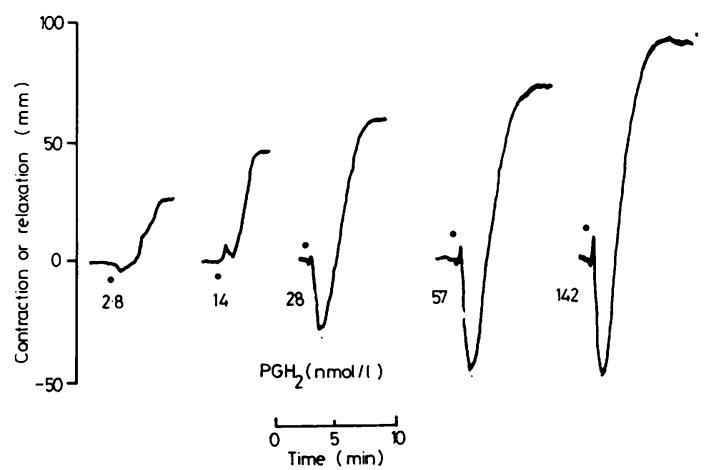

Fig. 3 Responses of baboon isolated vertebral artery to various doses of $\mathrm{PGH}_{2}$. Recordings as Fig. 1. The preparation was washed three times between each dose (records not shown).

The results of an experiment involving intravenous administration are given in Fig. 5. The upper record shows that there was pronounced dilatation of the major intracranial vessels (internal carotid; middle and anterior cerebral arteries). In contrast, the only extracranial artery measured (internal maxillary) showed profound vasoconstric-tion. This probably occurred as a consequence of the cardiovascular changes observed. These are illustrated in the lower record of Fig. 5. The first dose of $\mathrm{PGI}_{2}$ which caused the most substantiat changes in cerebral arterial calibre caused as moderate fall in pulse pressure and bradycardia the second dose of $\mathrm{PGI}_{2}$ which caused little further cerebral arterial dilatation, did produce severe hypotension and compensatory tachycardia, lasting 10 minutes. Thus arterial dilatation after intravenous $\mathrm{PGI}_{2}$ occurred in the absence of severe changes in blood pressure or heart rate.

The effects of $\mathrm{PGI}_{2}$ given intracisternally were also studied in one baboon; $\mathbf{P G I}_{2}$ was given through a needle inserted into the cisterna magna. $\mathrm{PGI}_{2} 31 \mu \mathrm{g} / \mathrm{kg}$ was administered by a slow infusion $(0.6 \mathrm{ml} / 1.5 \mathrm{~min})$. The effects on cerebral arterial calibre and the cardiovascular system are shown in Fig. 6 (upper and lower records respectively).

Immediately before $\mathrm{PGI}_{2}$ infusion the cerebral arteries showed some change in calibre in comparison with the baseline angiogram (time 0 , upper records). A second angiogram $10 \mathrm{~min}$ after infusion showed dilatation of all cerebral vessels, but this dilatation was not sustained. Thereafter substantial constriction developed in all intracranial vessels. These were a pronounced and prolonged bradycardia with slowly developing hypotension (Fig. 6 lower records). 


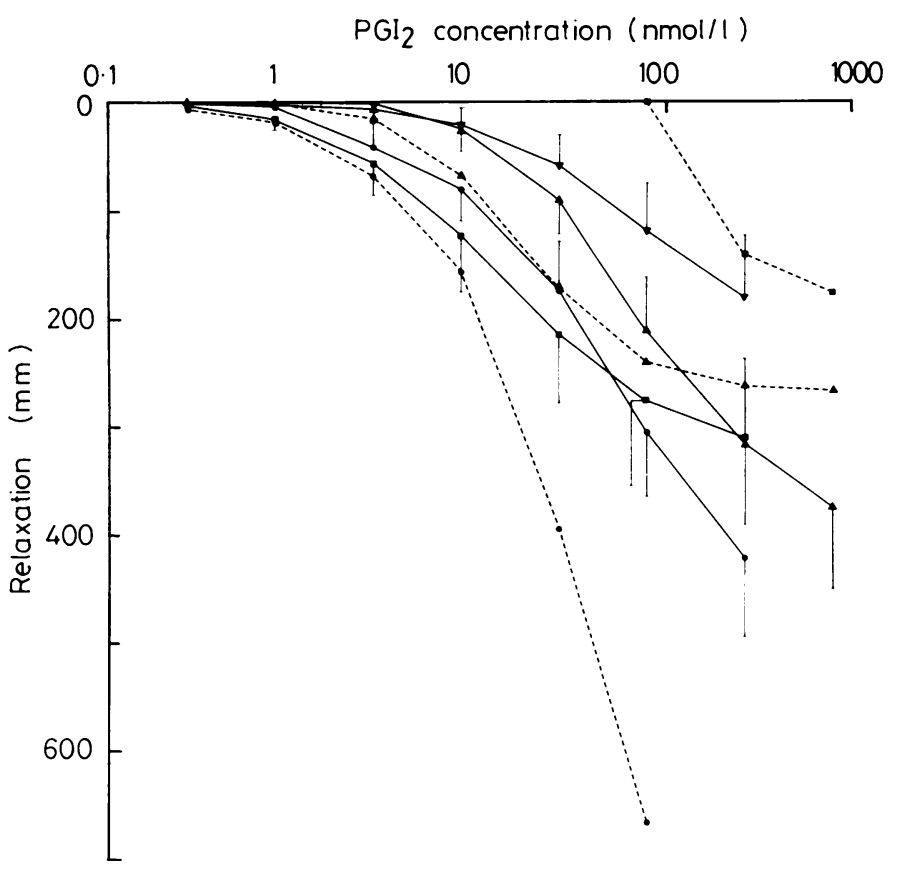

Fig. 4 Dose-response relationships for effects of $\mathrm{PGI}_{2}$ on baboon isolated cerebral and extracerebral arteries. Upper record, relaxation responses; lower record, contractile responses. Recordings as Fig. 2 except relaxations plotted as relaxation $(\mathrm{mm})$. For cerebral vessels values are the mean of three to five observations for relaxation and three to four observations for contraction. For extracerebral vessels the values were obtained in single experiments. Key to symbols as in Fig. 2.

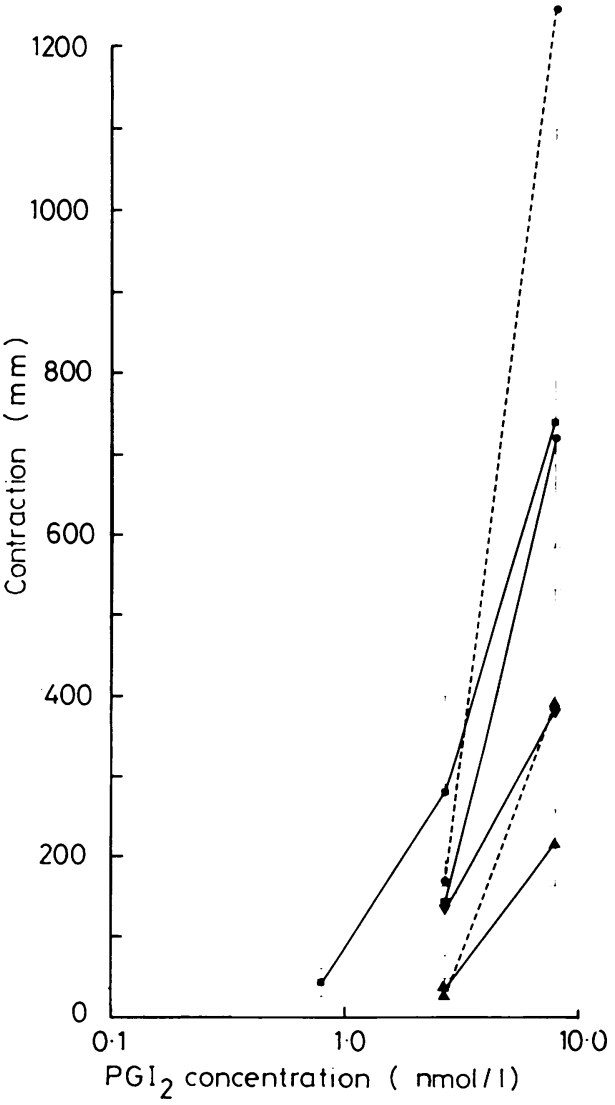



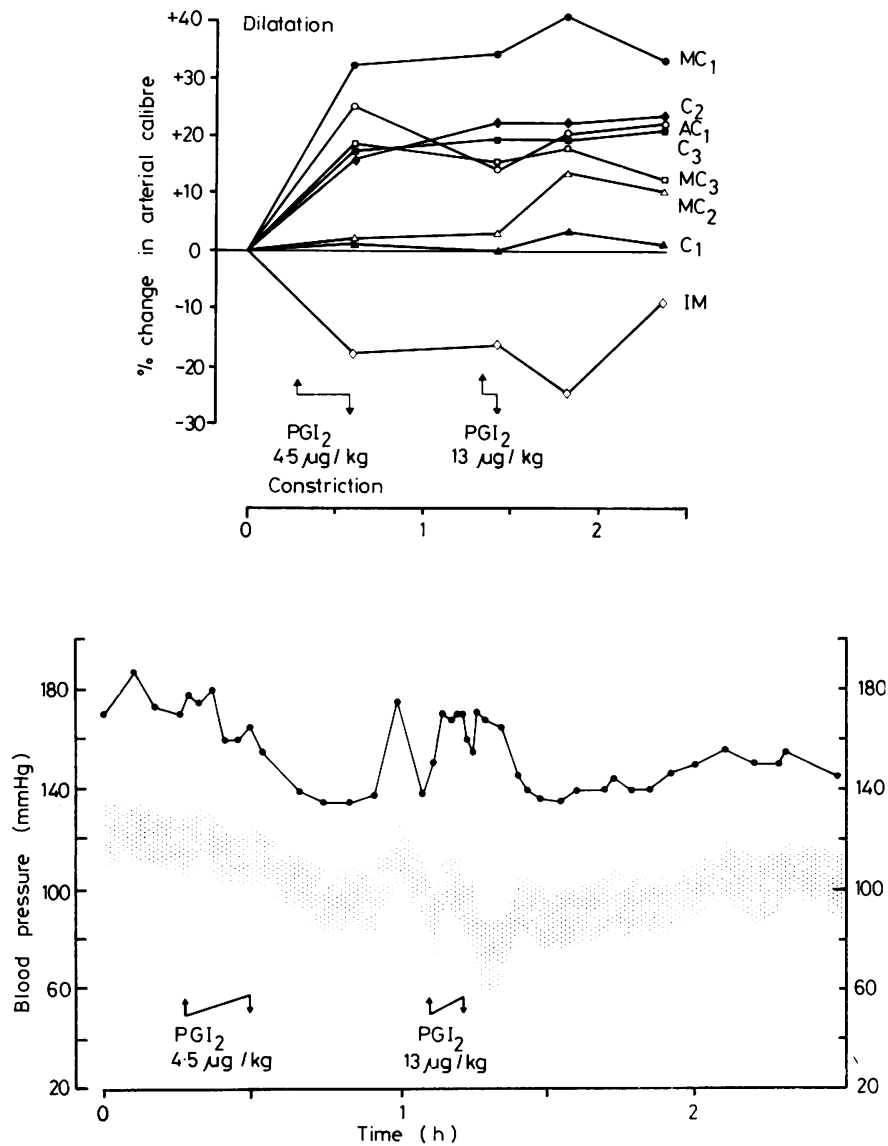

Fig. 5 Changes in calibre of baboon cerebral arteries and cardiovascular effects in vivo produced by two intravenous infusions of $\mathrm{PGI}_{2}(4.5 \mu \mathrm{g} / \mathrm{kg}$ and $13 \mu \mathrm{g} / \mathrm{kg})$ as indicated. The experiment was made in an anaesthetised baboon. Methods of recording responses are given in Methods and Boullin et al. (1978a). Upper records: changes in cerebral arterial calibre $(\%$ change ordinate) were calculated from the baseline angiograms made at zero time (hours, abscissa). Four subsequent angiograms were made at the times indicated by points on the graph. Lower records: heart rate $\longrightarrow \longrightarrow$ (beats/min) and systolic/diastolic blood pressure were recorded at the times indicated by values for heart rate $(\bullet)$. The stippled area represents the systolic/diastolic blood pressure $(\mathrm{mm} \mathrm{Hg}$ ) recorded at the same time as heart rate. Upper and lower records were obtained from the same animal; the duration of recording of cardiovascular changes was longer than the period of angiographic recordings. Symbols used to identify arteries are given in the legend to Fig. 6.
RESPONSES OF INDIVIDUAL ARTERIES IN VITRO The relative potencies of $\mathrm{PGH}_{2}$ and $\mathrm{PGI}_{2}$ and concentrations producing equivalent responses upon the individual arteries are given in Table 1. The vertebral artery is the most sensitive to the effects of both $\mathrm{PGH}_{2}$ and $\mathrm{PGI}_{2}$. Otherwise there is little variation in potency on the cerebral vessels. The concentrations of $\mathrm{PGH}_{2}$ in causing contraction are somewhat similar to the concentrations of $\mathrm{PGI}_{2}$ causing relaxation (see Discussion).

\section{COMPARISON WITH OTHER DRUGS}

We have previously reported the effects of dopamine and 5-HT on human and baboon isolated cerebral arteries (Boullin et al., 1977) and these will not be described in detail here.

Dopamine causes dose-dependent relaxation in low concentrations and contraction in high concentrations, while 5-HT produces only dosedependent contractions.
Table 2 gives a comparison of the effects of $\mathrm{PGH}_{2}$ and $\mathrm{PGI}_{2}$ with dopamine (DM), 5hydroxytryptamine (5-HT), and noradrenaline (NA). PGI $_{2}$ was 15 to 30 times more potent than DM in relaxing or contracting the anterior cerebral and vertebral arteries. On the other hand NA was much more potent than $\mathbf{P G I}_{2}$ in its contractile effects (eight to four times from Table 2). Finally Table 2 shows that $\mathrm{PGH}_{2}$ and 5 -HT were of approximately equal potency as vasoconstrictors.

\section{Discussion}

Although $\mathrm{PGH}_{2}$ has been shown by other workers to contract peripheral arteries in vitro including rabbit aorta, pig coronary artery, and human umbilical artery (Hamberg et al., 1975; Ellis et al., 1976; Tuvemo et al., 1976), there did not appear to be any previous reports other than our own of $\mathrm{PGH}_{3}$ contracting cerebral arteries in vitro (Boullin et al., 1979). Although our previous 

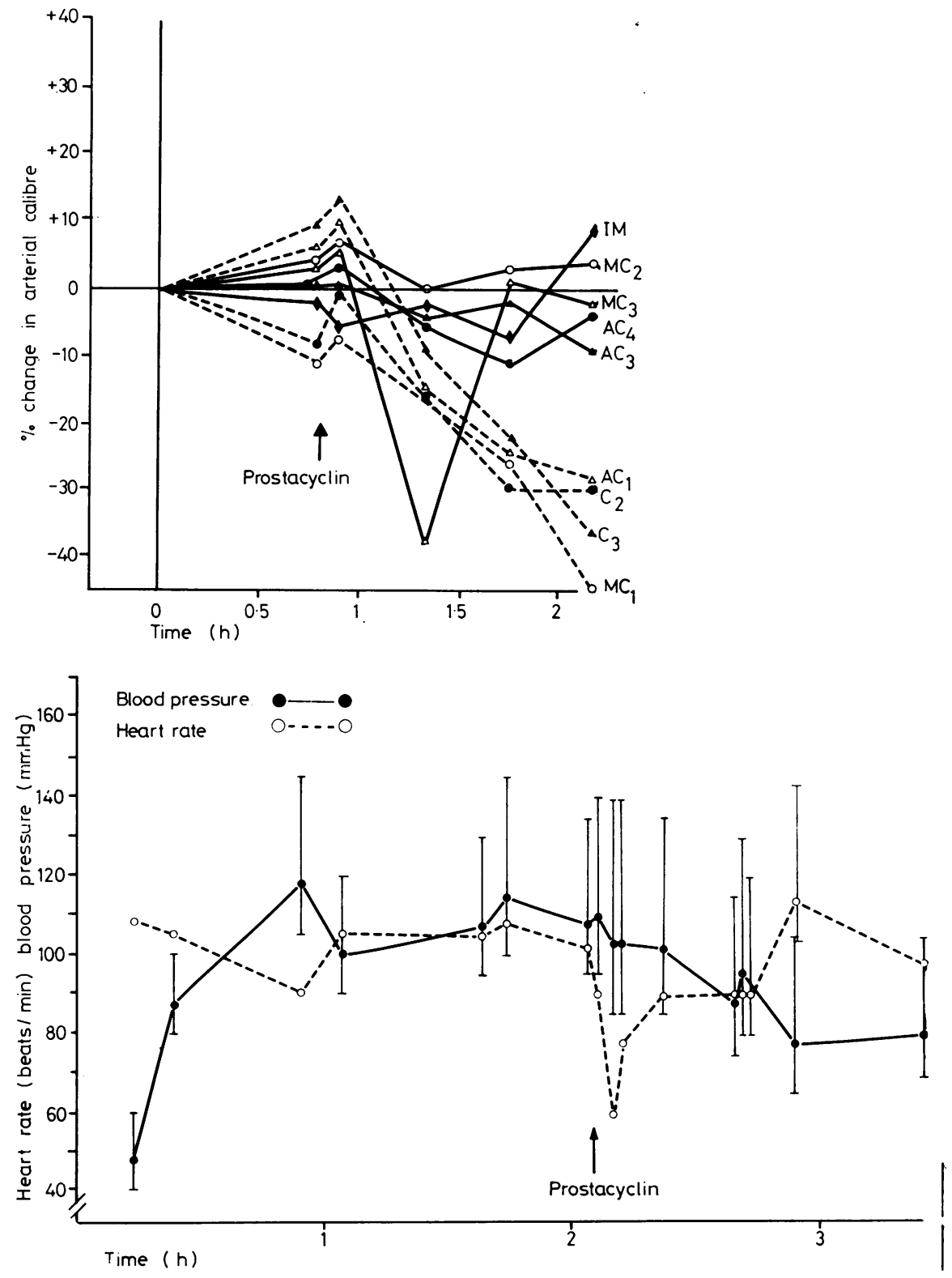

Fig. 6 Effect of intracisternal PGI2 on cerebral arterial calibre (upper records) and blood pressure and heart rate (lower records). At the arrow PGI $31 \mu \mathrm{g} / \mathrm{kg}$ was infused through a needle inserted into the cisterna magna. Infusion of $0.6 \mathrm{ml}$ was made in 90 seconds. The results of upper and lower records were obtained in a single animal. Data were recorded as described in Fig. 5 except that the systolic/diastolic blood pressure is indicated by bars attached to solid circles (๑). The following symbols are used to identify various portions of intracranial and extracranial arteries: $M C_{1}$, main trunk of middle cerebral; $C_{2}$, intracranial carotid; $A C_{1}$, main trunk of anterior cerebral; $C_{3}$, termination of intracranial internal carotid; $M C_{2}$, branch of $M C_{1} ; M C_{3}$, branch of a branch of $M C$, (ie branch of $M C_{2}$ ); $C_{1}$, extracranial internal carotid; IM, internal maxillary. 
Table 1 Concentrations and relative potencies of $\mathrm{PGH}_{2}$ and $\mathrm{PGI}_{2}$ causing equivalent responses of baboon isolated arteries

\begin{tabular}{|c|c|c|c|}
\hline Artery & $\begin{array}{l}\mathrm{PGH}_{2} \\
\text { contraction* }\end{array}$ & $\begin{array}{l}\mathrm{PGH}_{2} \\
\text { relaxation } \dagger \\
(\text { nmol } / \mathrm{l})\end{array}$ & $\begin{array}{l}P G I_{2} \\
\text { contraction* }\end{array}$ \\
\hline Vertebral & $\begin{array}{l}8 \pm 2.5 \\
(11.2)\end{array}$ & $\begin{array}{l}12 \pm 3.6 \\
(5.8)\end{array}$ & $\begin{array}{l}1300 \pm 550 \\
(6.2)\end{array}$ \\
\hline Basilar & $\begin{array}{l}32 \pm 1.8 \\
(2.8)\end{array}$ & $\begin{array}{l}45 \pm 9.0 \\
(1.6)\end{array}$ & $\begin{array}{l}2200 \pm 440 \\
(3.6)\end{array}$ \\
\hline MCA & $\begin{array}{l}17 \pm 2.0 \\
(5.3)\end{array}$ & $\begin{array}{l}55 \pm 11.4 \\
(1.3)\end{array}$ & $\begin{array}{l}2200 \pm 930 \\
(3.6)\end{array}$ \\
\hline Ant CA & $\begin{array}{l}21 \pm 8.3 \\
(4.3)\end{array}$ & $\begin{array}{l}70 \pm 17.2 \\
(1.0)\end{array}$ & $\begin{array}{l}4400 \pm 870 \\
(1.8)\end{array}$ \\
\hline Femoral & $\begin{array}{l}13 \\
(6.9)\end{array}$ & $\begin{array}{l}60 \\
(1.2)\end{array}$ & $\begin{array}{l}3500 \\
(2.3)\end{array}$ \\
\hline $\begin{array}{l}\text { Superior } \\
\text { mesenteric }\end{array}$ & $\begin{array}{l}90 \\
(1.0) \Delta\end{array}$ & $\begin{array}{l}18 \\
(3.9)\end{array}$ & $\begin{array}{l}8000 \\
(1.0)\end{array}$ \\
\hline
\end{tabular}

$\Delta$ Potency $=1$ (highest concentration causing recorded response). Values are the mean \pm SEM of three to five experiments; unqualified values are from one or two experiments.

* Produced by $100 \mathrm{~mm}$ contraction.

$+50 \%$ maximum response.

results indicate that baboon cerebral and extracerebral arteries possess prostacyclin synthetase activity, the conversion rates for $\mathrm{PGH}_{2}$ to $\mathrm{PGI}_{2}$ were very slow except for the vertebral and middle cerebral vessels (see Boullin et al., 1979). As the arteries were tested in vitro only a short while after death, and only the vertebral and femoral arteries showed evidence of relaxation by $\mathrm{PGH}_{2}$ it seems very likely that the constrictor effects of $\mathrm{PGH}_{2}$ represent a physiological effect and as such likely to occur in the intact animal. If this is true, endoperoxide formation may play a direct role in the maintenance of vasoconstrictor tone of arteries.

From the in vitro studies it appears that prostacyclin synthetase activity persists for only a short while post mortem in most baboon cerebral arteries. The exception is the vertebral artery which converted $\mathrm{PGH}_{2}$ to $\mathrm{PGI}_{2}$ up to 40 hours post mortem. Previously Boullin et al. (1979) found that the enzyme was also viable in the human basilar artery at this time, and in a variety of baboon arteries half to three hours after death. However, the percentage conversion of $\mathrm{PGH}_{2}$ to $\mathrm{PGI}_{2}$ was low in all arteries except the vertebral and middle cerebral arteries. The failure to find sufficient conversion of $\mathrm{PGH}_{2}$ to $\mathrm{PGI}_{2}$ to relax any baboon cerebral artery except the vertebral of in the current work, reinforces the view that $\frac{\bar{c}}{0}$ prostaglandin endoperoxides may exert direct 0 effects on cerebral vessels. An alternative possibility is that, in the absence of prostacyclin $\stackrel{5}{\text {. }}$. synthetase, prostaglandin endoperoxides are transformed rapidly to $\mathrm{PGE}_{2}$ which is a potent $?$ constrictor of human and baboon cerebral $\overrightarrow{\vec{\rho}}$ arteries (Boullin et al., 1976, 1977). It is not $\frac{\rho}{0}$ possible to determine the significance of prostacyclin synthetase in relation to responses of $\frac{\bar{\sigma}}{\omega}$ cerebral arteries without an extended study in $\vec{\Phi}$ different species.

The relaxing actions of $\mathrm{PGI}_{2}$ on isolated arteries क have been described earlier by Moncada et al. $\overrightarrow{0}$ (1977) for human abdominal vessels and by $\overrightarrow{\vec{H}}$ Boullin et al. (1979) for human and baboon cerebral vessels. In addition to confirming these results, we now show that intravenous $\mathrm{PGI}_{2}$ is a potent cerebral vasodilator. Doses in the $\mathrm{nmol} / \mathrm{kg}$ range produced dramatic and prolonged dilatation 0 of all cerebral arteries measurable on angiogram The effects were extremely prolonged (more tha $\ni$ one and a quarter hours, Fig. 5) and occurref in the absence of severe changes in blood pressurf and heart rate. These vasodilator actions were $?$ greater than in other experiments when there was severe hypotension and compensatory tachycardio s It is possible that the rather surprising failure $\overrightarrow{0}$ intra-arterial prostacyclin to cause cerebrât oै arterial dilatation was the result of the systemic hypotension. Du Boulay et al. $(1972,1973)$ showed that systemic hypotension resulted in as much as $20 \%$ constriction of the major cerebral arteries. The dilatation seen here in the face of hypoten- $\frac{0}{8}$ sion, therefore, was remarkable in view of the vasoconstriction which could be predicted.

Intracisternal prostacyclin also caused transient vasodilatation but this was followed by constriction. The haemodynamic changes were different from those seen with systemic prostacyclin, in that hypotension was not accompanied by tachycardia, but rather bradycardia. These effects

Table 2 Comparative effects of $\mathrm{PGH}_{2}, \mathrm{PGI}_{2}, \mathrm{DM}, \mathrm{NA}$, and 5-HT

\begin{tabular}{|c|c|c|c|c|c|c|c|}
\hline $\begin{array}{l}\text { Drug } \\
\text { Response }\end{array}$ & $\begin{array}{c}P G I_{2} \\
\downarrow * *\end{array}$ & $\underset{\uparrow *}{P G I_{2}}$ & $\begin{array}{l}D M \\
\downarrow * *\end{array}$ & $\begin{array}{l}D M \\
\uparrow *\end{array}$ & $\underset{\uparrow *}{P G H_{2}}$ & $\begin{array}{c}N A \\
\uparrow *\end{array}$ & $\begin{array}{l}5-H T \\
\uparrow *\end{array}$ \\
\hline & \multicolumn{7}{|c|}{ Drug concentration producing effect nmol/l } \\
\hline $\begin{array}{l}\text { Artery } \\
\text { Anterior cerebral } \\
\text { Vertebral }\end{array}$ & $\begin{array}{l}70 \\
12\end{array}$ & $\begin{array}{l}4400 \\
1300\end{array}$ & $\begin{array}{r}1100 \\
400\end{array}$ & $\begin{array}{r}100,000 \\
40,000\end{array}$ & $\begin{array}{r}21 \\
8\end{array}$ & $\begin{array}{r}500 \\
35\end{array}$ & $\begin{array}{l}14 \\
10\end{array}$ \\
\hline
\end{tabular}

$\downarrow=$ contraction; $\uparrow=$ relaxation; $*=$ response of $100 \mathrm{~mm}$ contraction; $* *=50 \%$ maximum response. 
could have been due to actions on the hypothalamus or other brain regions and would need much further study.

$\mathrm{PGI}_{2}$ is $15-30$ times more potent than dopamine in relaxing cerebral arteries. As dopamine has been tested in subarachnoid haemorrhage patients with cerebral arterial vasospasm (Boullin et al., 1977), there is the possibility that prostacyclin or more stable analogues may be of value in the treatment of spasm.

The constrictor effects of high concentrations of $\mathrm{PGI}_{2}$ seem unlikely to have any physiological significance because the rates of $\mathrm{PGI}_{2}$ synthesis by arteries and the heart are in the $\mathrm{ng} / \mathrm{g} / \mathrm{min}$ ( $\mathrm{pmol} / \mathrm{g} / \mathrm{min}$ ) range (De Deckere et al., 1977; Moncada et al., 1977; Boullin et al., 1979). There was no vasoconstrictor effect of $\mathrm{PGI}_{2}$ in situ, which probably reflects the rapid rate of hydrolysis of $\mathrm{PGI}_{2}$ to 6-oxo-PGF1 $\alpha$ (Moncada and Vane, 1977).

As regards the cause of vasospasm after subarachnoid haemorrhage, there is now evidence for the presence of unidentified vasoconstrictor factors in CSF of subarachnoid haemorrhage which are related to the severity of spasm and mortality (Blaso, 1978; Blaso and Boullin, 1978; Boullin and Blaso, 1978). Moreover in these same patients who died with angiographic evidence of vasospasm, Schianchi and Hughes (1978) have reported pathological changes in the endothelium of cerebral arteries known to have been in spasm during life (confirmed in experimental animal models by Tanake et al., 1978). As the endothelium is the site of prostacyclin synthetase, there is reason to implicate $\mathrm{PGI}_{2}$ in the aetiology of vasospasm after subarachnoid haemorrhage. Consequently vasospasm might involve defective prostacyclin synthetase leading to $\mathrm{PGI}_{2}$ deficiency, allowing prostaglandin endoperoxide $\left(\mathrm{PGH}_{2}\right)$ constrictor actions to become dominant. These defects in prostaglandin actions would be additional to the actions of the unidentified vasoconstrictor factors in CSF.

We are grateful to Mrs Victoria Aitken and Miss Sheila Redmond for expert technical assistance. D. J. Boullin is pleased to thank Dr J. R. Vane, Wellcome Laboratories Ltd, Beckenham, Kent, for supplies of $\mathrm{PGH}_{2}$ and synthetic $\mathrm{PGI}_{2}$. The Wellcome Trust provided generous financial support of this project.

\section{References}

Blaso, W. P. (1978). Pharmacological properties of cerebrospinal fluid after subarachnoid haemorrhage.
MSc Thesis, Bodleian Library, Oxford.

Blaso, W. P., and Boullin, D. J. (1978). Vasoconstrictor activity of cerebrospinal fluid from patients with cerebral arterial spasm. Journal of Physiology, 282, 39-40P.

Boullin, D. J., Adams, C. B. T., Mohan, J., Green, A. R., Hunt, T. M., Du Boulay, G. H., and Rogers, A. T. (1977). Effects of intracranial dopamine perfusion: behavioural arousal and reversal of cerebral arterial spasm following surgery for clipping of ruptured cerebral aneurysms. Proceedings of the Royal Society of Medicine, 70, 55-70.

Boullin, D. J., and Blaso, W. P. (1978). Pharmacological vasoactivity of cerebrospinal fluid correlates with cerebral arterial spasm and clinical deterioration after subarachnoid hemorrhage. Federation Proceedings, 37, 821.

Boullin, D. J., Du Boulay, G. H., and Rogers, A. T. (1978). Aetiology of cerebral arterial spasm following subarachnoid haemorrhage: evidence against a major involvement of 5-hydroxytryptamine in the production of acute spasm. British Journal of Clinical Pharmacology, 6, 203-215.

Boullin, D. J., Bunting, S., Blaso, W. P., Hunt, T. M., and Moncada, S. (1979). Responses of human and baboon arteries to prostaglandin endoperoxides and biologically generated and synthetic prostacyclin: their relevance to cerebral arterial spasm in man. British Journal of Clinical Pharmacology, 7, 139-147.

Boullin, D. J., Mohan, J., and Grahame-Smith, D. G. (1976). Evidence for the presence of a vasoactive substance (possibly involved in the aetiology of cerebral arterial spasm) in cerebrospinal fluid from patients with subarachnoid haemorrhage. Journal of Neurology, Neurosurgery, and Psychiatry, 39, 756-766.

De Deckere, E. A. M., Nugteren, D. H., and Tenhoor, F. (1977). Prostacyclin is the major prostaglandin released from the isolated perfused rabbit and rat heart. Nature, 268, 160-163.

Du Boulay, G. H., Symon, L., Shah, S., Dorsch, N., and Ackerman, R. (1972). Cerebral arterial reactivity and spasm after subarachnoid haemorrhage. Proceedings of the Royal Society of Medicine, 65, 20-82.

Du Boulay, G. H., Symon, L., Ackerman, R. H., Kendall, B. E., and Shah, S. H. (1973). The reactivity of the spastic arteries. Neuroradiology, $5,37-39$.

Ellis, E. F., Oelz, O., Roberts, L. J., Payne, N. A., Sweetman, B. J., Nies, A. S., and Oates, J. A. (1976). Coronary arterial smooth muscle contraction by a substance released from platelets: evidence that it is thromboxane $A_{2}$. Science, 193, 1135-1137.

Hamberg, M., Hedqviist, P., Strandberg, K., Svensson, J., and Samuelsson, B. (1975). Prostaglandin endoperoxides. IV Effects on smooth muscle. Life Sciences, 16, 451-462.

Moncada, S., and Vane, J. R. (1977). The discovery of prostacyclin-a fresh insight into arachidonic acid metabolism. In Biochemical Aspects of Prosta- 
glandins and Thromboxanes, pp. 155-177. Edited by N. Kharasch and J. Fried. Academic Press: New York.

Moncada, S., and Vane, J. R. (1978). Prostacyclin, platelet aggregation and thrombosis. In Platelets: $A$ Multidisciplinary Approach, pp. 239-258. Edited by G. De Gaetano and S. Garattini. Raven Press: New York.

Moncada, S., Gryglewski, R. J., Bunting, S., and Vane, J. R. (1976). An enzyme isolated from arteries transforms prostaglandin endoperoxides to an unstable substance that inhibits platelet aggregation. Nature, 263, 663-665.

Moncada, S., Higgs, E. A., and Vane, J. R. (1977). Human arterial and venous tissues generate prostacyclin (prostaglandin $\mathrm{X}$ ), a potent inhibitor of platelet aggregation. Lancet, 1, 18-20.

Needleman, P., Raz, A., Kulkarni, P. S., Pure, E., Wyche, E., Denny, S. E., and Isakson, P. C. (1977). Biological and chemical characterisation of a unique endogenous vasodilator prostaglandin produced in isolated coronary artery and in intact perfused heart. In Biochemical Aspects of Prostaglandins and Thromboxanes, pp. 199-214. Edited by N. Kharasch and J. Fried. Academic Press: New York.

Schianchi, P. M., and Hughes, J. T. (1978). Cerebral artery spasm: histological changes in necropsies of cases of subarachnoid hemorrhage. Advances in Neurology, 20, 521-534.

Starling, L. M., Boullin, D. J., Grahame-Smith, D. G., Adams, C. B. T., and Gye, R. S. (1975). Responses of isolated human basilar arteries to 5-hydroxytryptamine, noradrenaline, serum, platelets and erythrocytes. Journal of Neurology, Neurosurgery, and Psychiatry, 7, 650-656.

Tanake, Y., Sakata, K., Yamada, H., Ito, T., and Takada, M. (1978). Cerebral vasospasm and ultrastructural changes in cerebral arterial walls. An experimental study. Journal of Neurosurgery, 49, 229-238.

Tuvemo, T., Strandberg, K., Hamberg, M., and Samuelsson, B. (1976). Formation and isolation of prostaglandin endoperoxides in the isolated human umbilical artery. Acta Physiologica Scandinavica, 96, 145-149. 